\title{
Pain and suffering: the boy and the lizard
}

\author{
Giorgio Bordin
}

Received: 10 May 2012/ Accepted: 25 May 2012/Published online: 20 July 2012

(C) Springer-Verlag 2012

The life of mankind cannot be spared from pain and suffering.

The word "pain" comes from the Latin poena, which means punishment and assumes a crime. "Suffering", shares its root with "supporting", and means "to bear something". The idea that pain comes into the life of man due to his own faults belongs to many cultures. It is far from the aim of this report to deal with such a matter, but it is a fact that no man, if seriously engaged with his life, can avoid to ask: why suffer?

When Caravaggio depicted this canvas (Boy bitten by a lizard, Fig. 1) in two copies in 1595 and 1596, he was certainly inspired by a drawing (Asdrubale bitten by a crawfish, Fig. 2) made in 1554 by a very appreciated paintress: Sofonisba Anguissola.

Crawfish, scorpions or cancer (Latin for crab), which were in the past (Pliny, Cicero) considered to be and drawn as the same animal, were used in some early Renaissance literature and pictures as a symbol of evil, or of a wrong way of life; the harmless lizard, too, was connected with bad feelings and the desire of revenge. Allegorical etchings of children trying to touch scorpions, spiders or crawfishes were published in fabulae (fables) and emblemata (symbols) with moralistic, educational intention, to show the risks of failing to discern good from evil. A bit later, the painters also began to introduce comical implications in these themes and treat them on the basis of physiognomic studies, which are evident in Anguissola's and Caravaggio's works [1].

These later pictures depart from the allegoric genre to enter a deep introspective style of portraiture, where

G. Bordin ( $\square)$

Hospital Piccole Figlie, Parma, PR, Italy

e-mail: gbordinas@inwind.it emotion and mood become key elements of the paintings. Pain is described as it is manifested, irrespective of other symbolic meanings, and is in fact addressed at a very physical level. Physiologically speaking, pain pertains to exteroceptive sensibility: first perceived through non-specific receptors, it is carried by neurological fibers to the brain, where only there does it register as pain, providing to one's consciousness both discriminative (epicritic) and affective (protopathic) features.

Compare the two images; they are quite similar in structure, but deeply different in perception and meaning.

Both the subjects withdraw their right arm, after the bite.

Anguissola drives our attention toward the emotive side of pain, flaunting her best physiognomic skills, which

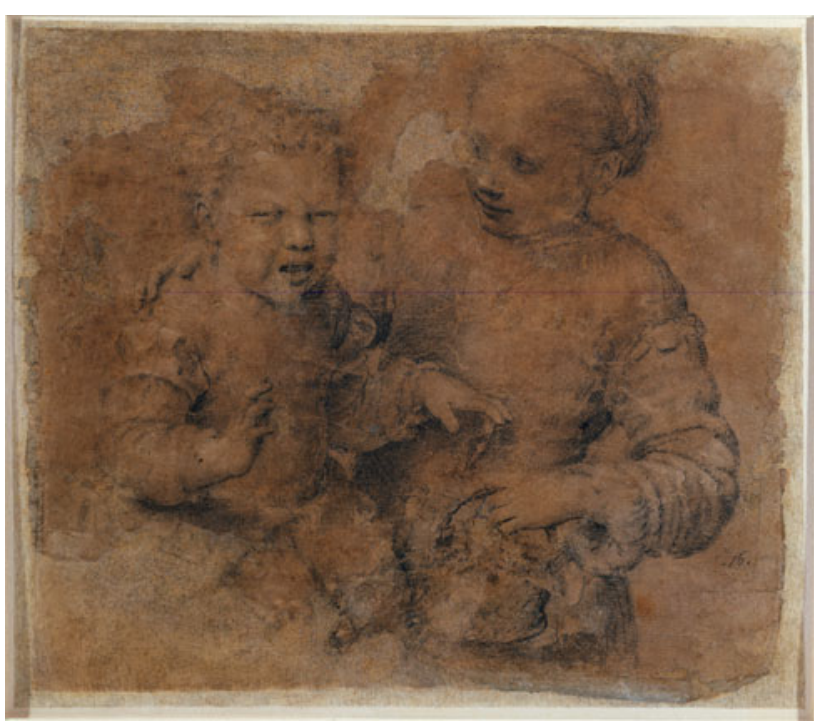

Fig. 1 Sofonisba Anguissola (1535-1635): Asdrubale bitten by a crawfish. 1554. Black chalk and charcoal on brown paper. Capodimonte museum. (C) 2012. Foto Scala, Firenze 


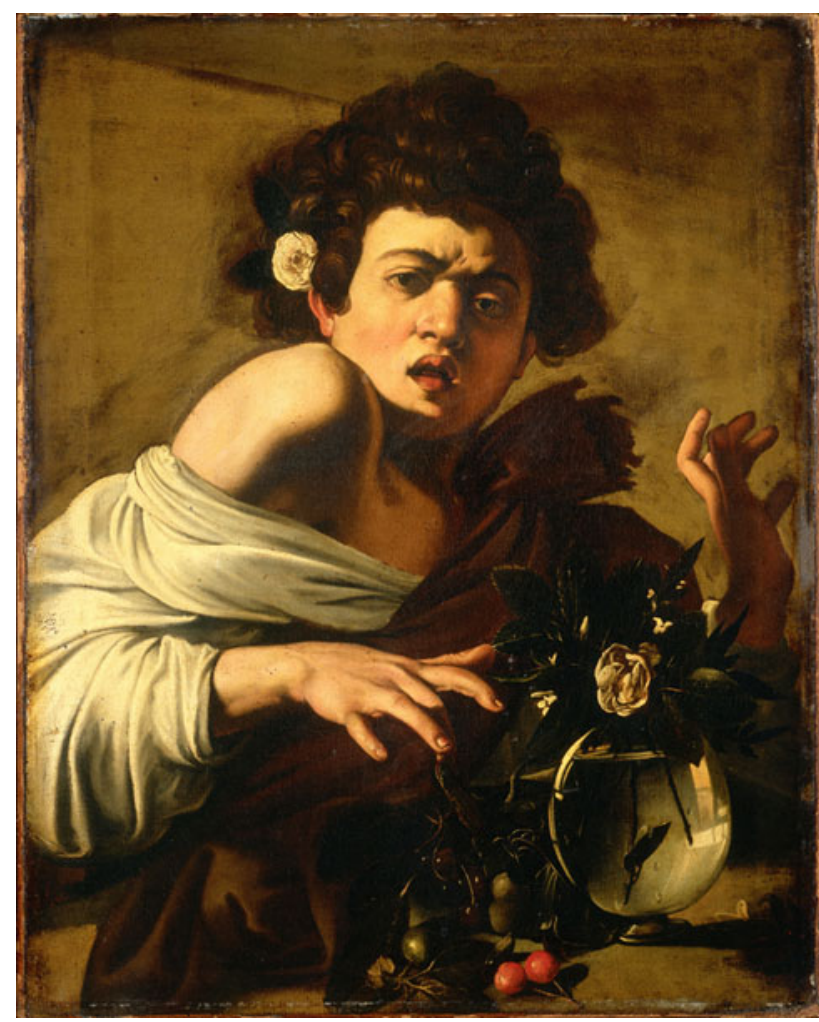

Fig. 2 Caravaggio (Michelangelo Merisi da Caravaggio 1571-1610): Boy bitten by a Lizard Firenze, Longhi collection. (C) 2012. Foto Scala, Firenze

Renaissance painters and sculptors extensively explored and refined in all forms after Leonardo's teaching. Her painting captures a moment just after the painful experience, where the child starts to cry and arrests his gesture in a sort of immobility, as children often do. The mother, standing in an unbalanced posture, gives us the feeling of movement, and counterbalances the scene with her quiet and compassionate smile. Pain isn't so far the main subject; a tender, everyday family scene is caught in its intimacy with remarkable introspection.

Caravaggio's boy is alone. There is no family scene here, no mother or friend or wife to stay with. No longer a child, a young man - Man himself - fills the canvas with his dynamic figure. If the former painting could be like the memory of an intimate scene, here we are viewing a frozen frame of a movie.

This canvas catches the exact moment of the perception of pain, offering at the same time the better visual depiction of the monosynaptic withdrawal reflex arc. This reflex begins as soon as the stimulus reaches the spinal cord, before all sensory information get sent to the brain for analysis and be consciously recognised, and so also before reason and culture, on behalf of the deepest inner animal instinct. The advantage of this reflex arc is in fact to provide a protective response without the need to wait for instructions from the brain.

Here, two points are to be highlighted.

The first: The reflex arc is today a well known neurological mechanism, but it was unknown in Caravaggio's time. The Cartesian idea (René Descartes was born the same year of this painting: 1596) of the human body conceived as a machine (the movement activities of which are stimulated by the movement of nerve fluid) is one direct ancestor of mechanistic theory in biology [2], but the importance of Descartes was not recognised until many years later, in the nineteenth century, as T.H. Huxley extensively described in his essay on reflex action [3]. The neurological basis for the reflex could only have been formulated in the last decades of the nineteenth century, with the discovery of the "animal electricity", after related studies by Galvani and Volta [4]. Caravaggio's work, capable of describing with awesome perfection a neurological sign not already scientifically appreciated, reminds us that careful observation can feed knowledge, providing access to truths that cannot be explained by reason alone, but which can be accepted through the recognition that comes from an experience.

The second: As previously stated, pain can't be reduced to a simple perception because it also involves emotional response in its affective dimension. In fact, if the withdrawn arm illustrates the physical nature of pain, the expression of the face tells us also of a psychological dimension, ignited together within the reflex arc, before the brain's decryption of the event. Here, the genius of the painter changes an animal grimace of aching into a deep, interrogative human look that asks us the meaning of that pain.

The innate, original structure of man can't avoid this quest for happiness.

\section{References}

1. de Klerck B (1994) Sofonisba Anguissola e le sue sorelle. Leonardo Arte, Milano, pp 274-277

2. Phillips DC (1971) James Dewey, and the reflex arc. J Hist Ideas 32(4):555-568

3. Huxley TH (1881) On the hypothesis that animals are automata, and its history. Science and Culture, London

4. Liddell EGT (1960) The discovery of reflexes, Oxford 